\title{
BMJ Open Qualitative critical incident study of patients' experiences leading to emergency hospital admission with advanced respiratory illness
}

\author{
Eleni Karasouli, ${ }^{1}$ Daniel Munday, ${ }^{2}$ Cara Bailey, ${ }^{3}$ Sophie Staniszewska, ${ }^{4}$ \\ Alistair Hewison, ${ }^{3}$ Frances Griffiths ${ }^{2}$
}

To cite: Karasouli E, Munday D, Bailey C, et al. Qualitative critical incident study of patients' experiences leading to emergency hospital admission with advanced respiratory illness. BMJ Open 2016;6:e009030. doi:10.1136/bmjopen-2015009030

- Prepublication history for this paper is available online. To view these files please visit the journal online (http://dx.doi.org/10.1136/ bmjopen-2015-009030).

Received 9 June 2015 Revised 4 September 2015 Accepted 14 September 2015

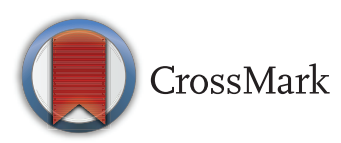

For numbered affiliations see end of article.

Correspondence to

Dr Eleni Karasouli;

E.Karasouli@warwick.ac.uk

\section{ABSTRACT}

Objectives: The high volume of emergency admissions to hospital is a challenge for health systems internationally. Patients with lung cancer and chronic obstructive pulmonary disease (COPD) are frequently admitted to hospital as emergency cases. While the frequency of emergency admission has been investigated, few studies report patient experiences, particularly in relation to the decision-making process prior to emergency admission. We sought to explore patient and carer experiences and those of their healthcare professionals in the period leading up to emergency admission to hospital.

Setting: 3 UK hospitals located in different urban and rural settings.

Design: Qualitative critical incident study.

Participants: 24 patients with advanced lung cancer and 15 with advanced COPD admitted to hospital as emergencies, 20 of their carers and 50 of the health professionals involved in the patients' care.

Results: The analysis of patient, carer and professionals' interviews revealed a detailed picture of the complex processes involved leading to emergency admission to hospital. 3 phases were apparent in this period: self-management of deteriorating symptoms, negotiated decision-making and letting go. These were dynamic processes, characterised by an often rapidly changing clinical condition, uncertainty and anxiety. Patients considered their options drawing on experience, current and earlier advice. Patients tried to avoid admission, reluctantly accepting it, albeit often with a sense of relief, as anxiety increased with worsening symptoms.

Conclusions: Patients with advanced respiratory illness, and their carers, try to avoid emergency admission, and use logical and complex decisionmaking before reluctantly accepting it. Clinicians and policy-makers need to understand this complex process when considering how to reduce emergency hospital admissions rather than focusing on identifying and labelling admissions as 'inappropriate'.

\section{INTRODUCTION}

Emergency hospital admissions are a global challenge, despite significantly different

\section{Strengths and limitations of this study}

- This study is the first to explore the experiences of patients, together with those of their carers and associated healthcare professionals, with advanced respiratory illness in the time leading up to emergency admission.

- This study is also the first one to explore in depth the decision-making process leading up to emergency admission.

- As this study recruited patients admitted to hospital as emergency cases, the experiences of patients treated at the emergency department but not admitted to the hospital are not captured. However, this enabled us to provide rare insight into the experiences of patients with lung disease near the end of life, who can be seen as most vulnerable.

systems of care. ${ }^{1}$ Emergency hospital admissions, account for $35 \%$ of all hospital admissions, ${ }^{2}$ and $67 \%$ of all hospital inpatient bed days in England. 'Hospital Episode Statistics' in England defines all unplanned admissions as emergencies. They are an increasing source of pressure on health system resources internationally, ${ }^{4}$ and are a particularly costly form of healthcare.

It is estimated that emergency admissions cost the National Health Service (NHS) $£ 12.5$ billion per annum. ${ }^{3}$ Around 160000 emergency cancer admissions ${ }^{5}$ and 135000 chronic obstructive pulmonary disease (COPD) admissions occur in the UK per year. $^{6}$ COPD is the second most common reason for a medical admission, ${ }^{7}$ and lung cancer is the commonest cancer among patients admitted as emergencies. ${ }^{8}$ In addition, emergency admissions are distressing for both patients and carers, and have a negative impact on their quality of life, ${ }^{4}$ affecting patients with cancer ${ }^{9}$ and COPD. ${ }^{10}$

Understandably, there are concerns over whether all emergency admissions are 
necessary. ${ }^{11}$ Although the evidence for effectiveness of strategies for preventing emergency admissions, including those of patients with lung cancer and COPD, is limited, ${ }^{12} 13$ there is a common assumption that emergency admissions can be avoided through the provision of better primary care. ${ }^{13}$

The prominence of emergency admissions as a policy challenge has generated considerable research interest both in the UK and internationally, particularly with regard to reducing admissions. ${ }^{14}{ }^{15}$ Reasons for emergency admissions have largely been explored through medical record review. ${ }^{16}$ Few studies have explored reasons for emergency admission, or the process of decision-making, from the perspective of patients with advanced chronic life-limiting illnesses. ${ }^{16} 17$

Policy and service priorities over the last decade have identified the need to develop a better understanding of patient experience to improve services for direct patient benefit. ${ }^{18}$ Consequently, understanding patient experience as an indicator of quality has become increasingly important, reflecting awareness of this type of patientbased evidence in evaluations of the effectiveness, acceptability and appropriateness of care. ${ }^{18} 19$

The reason for emergency admission in advanced lung cancer and COPD may be complex. In order to examine what happens for the patient in the lead up to an emergency admission, it was necessary not only to consider the immediate causal factors, such as the medical symptoms, but also the broader contextual factors, particularly the psychosocial and organisational issues, which influenced the admission process. In view of this, this study sought to collect accounts of emergency admission from patients and their informal carers, and also from healthcare professionals in community and hospital settings.

\section{METHODS}

\section{Study design and data collection}

The study followed a 'critical incident' approach. ${ }^{20}$ The 'critical incident' is the emergency hospital admission of patients with advanced lung cancer or COPD. The analysis encompasses the context of the admission, including the admission process, the time leading to it, and the perspectives of the different participants involved. The critical incident cases were built by conducting semistructured interviews and exploring the experiences of patients, their informal carers, and key health professionals involved in their admission, both in the community and in the hospital. The interviews explored the following areas: the symptoms the patient was experiencing and their progress over time, social context and medical management prior to admission; the patient and carer's roles in self-management; healthcare staff's involvement in the critical incident; process and experience of admission; and identification of factors that could potentially have prevented the emergency admission. The interview schedules were developed by drawing on a previous study of emergency admission, ${ }^{17}$ a brief exploration of the health service contexts by key informant interviews with clinicians based at the recruitment hospital sites, and a literature review to explore the wider context.

The interviews were conducted as soon as possible after admission (while patients were still hospitalised, or soon after discharge at patients' residences) and lasted between 20 and $40 \mathrm{~min}$. The interviews with carers generally coincided with the patient interviews in accordance with participants' preferences. Up to two community and hospital health professionals nominated by the patient were interviewed to explore the reasons for admission from their perspective, and to obtain further information about the participant's situation. Participant recruitment stopped when data saturation was reached. The interviewers $(\mathrm{EK}, \mathrm{CB}$ and $\mathrm{FB}$ ) were experienced researchers trained in interviewing, with either a psychology (EK) or nursing ( $\mathrm{CB}$ and $\mathrm{FB}$ ) background.

\section{Setting and recruitment}

Three hospitals in one region of England participated in the study: site A was a University Hospital Foundation Trust in a city of 300000 inhabitants, site B was a District General Hospital NHS Trust in a market town serving a large rural area, with a total population of 180000 , and site $\mathrm{C}$ was a large inner city NHS Foundation Trust Hospital serving a diverse population of approximately 1 million.

At site A, a hospital research nurse screened the emergency department (ED) admission list for eligible patients, and the respiratory Clinical Nurse Specialist (CNS) advised on patients' suitability. At site B, the respiratory CNS team identified participants. At site C, participants were identified by both hospital research nurses and the CNS team. Recruitment took place over 18 months to take account of seasonal variation in admission rates. A clinical assessment was undertaken by the respiratory CNS prior to all interviews to ensure patients were well enough to participate (ie, in a stable condition and without showing excessive signs of distress). Recruitment of informal carers and healthcare professionals was based on patients' nominations of those most involved with the patients' care.

\section{Participants}

All patients who took part in the study had a known diagnosis of incurable lung cancer, or had advanced COPD receiving home oxygen (used as a marker to enable rapid identification of patients). The informal carers were either family members or close friends. The community healthcare professionals were general practitioners (GPs), district nurses, community matrons and specialist palliative care nurses. The hospital healthcare professionals interviewed were consultants, specialist nurses and ward sisters. 


\section{Data analysis}

Audio recordings of interviews were transcribed verbatim by a professional transcription company. All transcriptions were checked by the research team for accuracy. Transcriptions were anonymised and entered into NVivo for analysis. Initially, the immediate reason for admission and the admission process for each patient were determined from the interview text of the patient and informal carer interviews by two research team members (EK and DM) with any differences being resolved by discussion.

Two analytical approaches were used; cross-case analysis $^{21}$ and thematic analysis. ${ }^{22}$ Cross-case analysis was undertaken to map out the steps taken by each patient in the admission process (tables 1 and 2). Cross-case analysis allows the comparison of cases and provides opportunities to learn from different cases. ${ }^{23}$ Thematic analysis was undertaken to explore and understand variation in patients' experience of the contextual factors contingent on the reason for admission, and to explore the decision-making process employed leading to admission. A template approach ${ }^{24}$ was used to assist the thematic analysis by developing a coding template, which summarised identified themes. Two members of the team (EK and FB) developed the initial coding template, which was derived from the interview schedule and by repeated readings of the transcripts. The template was then used to code all transcripts (EK and FB). As a further quality control measure, a third team member (CB) randomly selected four transcripts and applied the template independently confirming a high level of agreement. Finally, emerging themes were identified by EK, CB, DM and AH. The team then linked the emerging themes and their dynamic nature by developing a model (figure 1) that links the themes to the wider context.

Members of the project steering group and service user group were consulted throughout all steps of the analysis, by collectively reading a sample of transcripts and discussing them during analysis meetings. The emerging findings and the model (figure 1) were presented to and discussed with the Macmillan Cancer and Palliative Care Research Collaborative (MacPaCC), conferring a degree of face validity on the results. MacPaCC comprises expert academics with clinical backgrounds.

Table 1 Reasons and process of admission of patients with advanced chronic obstructive pulmonary disease

\begin{tabular}{ll}
\hline $\begin{array}{l}\text { Medical symptoms triggering } \\
\text { emergency admission }\end{array}$ & $\begin{array}{l}\text { Emergency } \\
\text { admission process }\end{array}$ \\
\hline Breathlessness ( $n=14)$ & $\begin{array}{l}999 \text { emergency call } \\
(n=10) G P(n=4)\end{array}$ \\
$\begin{array}{l}\text { Severe pain (described as chest } \\
\text { pain due to fractured ribs and } \\
\text { pneumonia-no clear history of } \\
\text { fall) }(n=1)\end{array}$ & $\begin{array}{l}999 \text { emergency call } \\
(n=1)\end{array}$ \\
\hline
\end{tabular}

Their professional experiences highly matched the findings of the analysis, and the subsequent discussions provided further in-depth understanding to the meaning of some of the results. By employing such an extensive approach involving not only the immediate research team, but also a steering group, a service user group and a group of experts (MacPaCC), we made sure that the researchers' own actions, values and perceptions impacting on the research setting and affecting data collection and analysis was minimised, ${ }^{25}$ avoiding such a common pitfall among qualitative studies.

\section{RESULTS}

\section{Participants characteristics}

Fifty-five patients met the inclusion criteria and were considered well enough to be approached. Of the 55 patients approached, 16 subsequently did not take part for reasons such as: patients declined, deterioration in health, patients were unable to communicate, patients died, researchers were unable to contact patients due to discharge or transfer. A total of 39 patients were interviewed. Twenty of the patients' informal carers (13 partners, 6 daughters/sons and 1 friend), and 50 of the health professionals involved in the patients' care (27 hospital healthcare professionals, and 23 community healthcare professionals) were also interviewed. Twenty-three of the patients were male and 16 were female. A total of 16 patients were admitted to hospital during 'normal' general practice opening hours (8:00 to 18:00, Monday to Friday). Twelve patients were admitted out of hours during weekdays, and 11 patients were admitted out of hours at weekends. Table 3 further describes patients according to their medical condition.

\section{Clinical reasons for and the process of admission}

The reasons for admission are listed in tables 1 and 2 . The majority of patients with COPD were admitted with severe shortness of breath, usually after a relative had summoned an emergency ambulance, or following contact with a GP. Shortness of breath was also a common reason for admission for patients with lung cancer, but a number of patients were also admitted with pain, falls or acute medical problems which needed investigation. When an ambulance was called without prior contact with a community professional, it was due to an acute and severe problem.

\section{Phases leading to admission}

The data analysis shows the decision-making process that the patients undertook which led to emergency hospital admission. In order to understand this process, there was a need to examine not only the physical symptoms that the patient experienced, but also their psychosocial context. The analysis suggests that the patient goes through a process of three distinct phases which lead to an emergency admission: self-management as the condition deteriorated, negotiated decision-making, and 


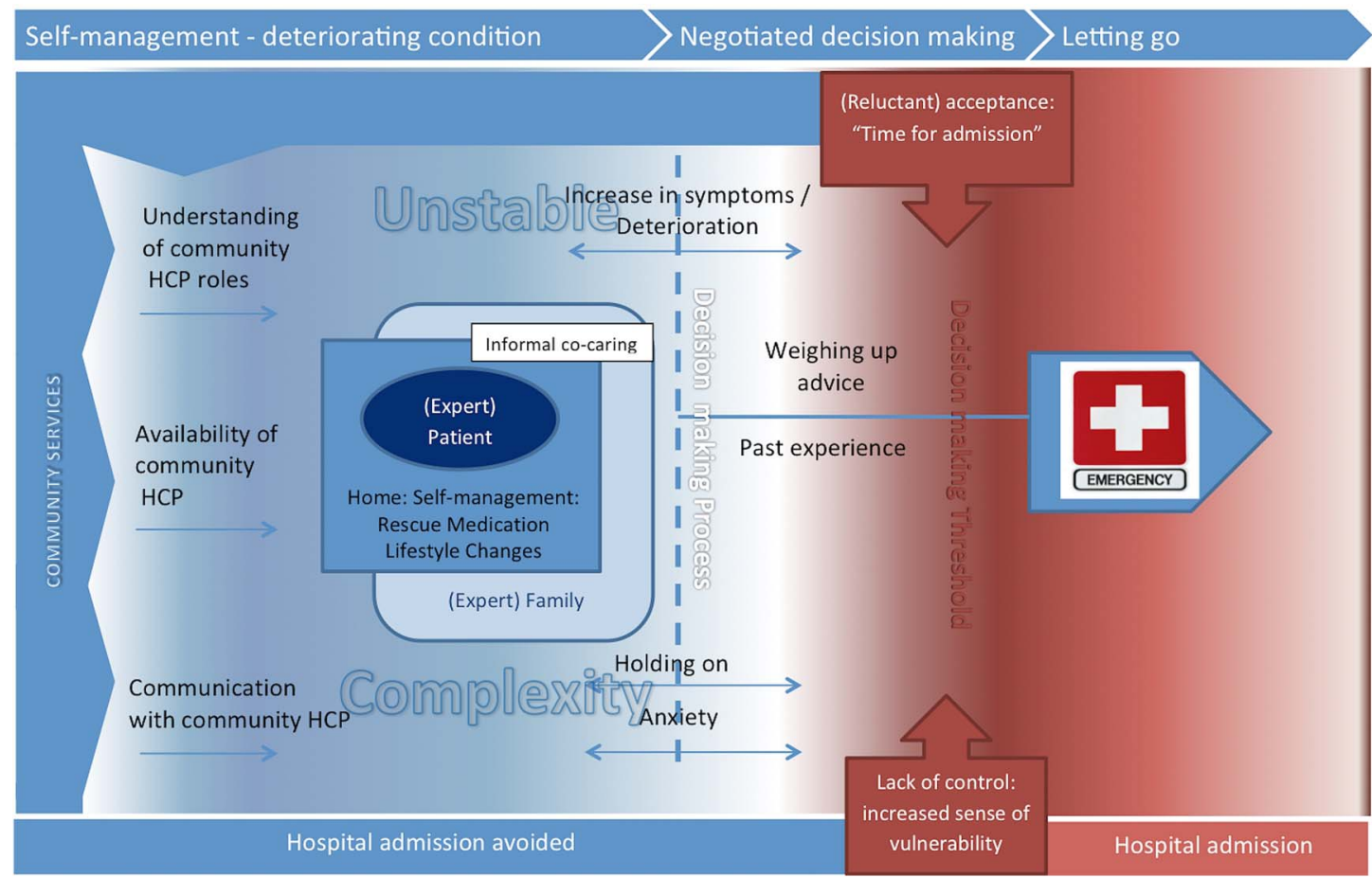

Figure 1 Diagram of complex decision-making.

letting go. Each phase marks specific changes, both physical and psychological, which are characterised by complex interaction, until the patient reaches a threshold where emergency admission is seen as the only viable option. Figure 1 summarises the nature of each

Table 2 Reasons and process of admission of patients with lung cancer

\begin{tabular}{ll}
\hline $\begin{array}{l}\text { Medical symptoms triggering } \\
\text { emergency admission }\end{array}$ & $\begin{array}{l}\text { Emergency } \\
\text { admission process }\end{array}$ \\
\hline Breathlessness $(n=7)$ & $\begin{array}{l}999 \text { emergency call } \\
(n=6)\end{array}$ \\
$\begin{array}{l}\text { GP }(n=1) \\
\text { onset/increase) ( } n=5)\end{array}$ & $\begin{array}{l}99 \text { emergency call } \\
(n=3) \\
\text { Complex process } \\
(n=1)\end{array}$ \\
& $\begin{array}{l}\text { Community nurse } \\
(n=1)\end{array}$ \\
$\begin{array}{l}\text { Other medical problem (eg, heart } \\
\text { or DVT) ( } n=3)\end{array}$ & GP (n=3) \\
$\begin{array}{l}\text { Falls accompanied by weakness } \\
\text { and deterioration ( } n=4)\end{array}$ & $\begin{array}{l}999 \text { emergency call } \\
(n=3)\end{array}$ \\
$\begin{array}{l}\text { Infection (not treatment related, eg, } \\
\text { Community nurse }\end{array}$ & $\begin{array}{l}\text { Relative }(n=1) \\
\text { GP }(n=1)\end{array}$ \\
$\begin{array}{l}\text { Infection (following chemotherapy) } \\
\text { (n=1) }\end{array}$ & Relative ( $n=1)$ \\
$\begin{array}{l}\text { Problem unrelated to underlying } \\
\text { cancer (eg, cholecystitis and } \\
\text { unclear problem) ( } n=2)\end{array}$ & Unknown (n=2) \\
\hline DVT, deep vein thrombosis; GP, general practitioner.
\end{tabular}

phase in the context of what we call 'unstable complexity', as the patient's condition deteriorates until admission occurs. Below, we present the exploration of the variation of experience of these phases.

\section{Self-management during deterioration of condition}

Within the familiarity of their own home, patients, often with the support of informal carers, lived with their illness, managing its effects (including exacerbations) in a variety of ways. While this was affected by their social circumstances, the way the illness impacted on their lives, and the access they had to community healthcare, patients managed the day-to-day fluctuations in their health. Consequently, patients, together with their informal carers, had become experts in understanding their illness and managing its effects. This expertise, along with community-based healthcare professionals'

Table 3 Patients characteristics according to medical condition

\begin{tabular}{|c|c|c|c|c|}
\hline $\begin{array}{l}\text { Medical } \\
\text { condition }\end{array}$ & $\mathbf{N}$ & $\begin{array}{l}\text { Gender } \\
\text { (male/ } \\
\text { female) }\end{array}$ & $\begin{array}{l}\text { Mean age } \\
\text { (years) }\end{array}$ & $\begin{array}{l}\text { Died within } \\
3 \text { months of } \\
\text { interview }\end{array}$ \\
\hline $\begin{array}{l}\text { Lung } \\
\text { cancer }\end{array}$ & 24 & $14 / 10$ & $\begin{array}{l}72.5 \\
\text { (median: } \\
71, \text { range: } \\
55-90 \text { ) }\end{array}$ & 14 \\
\hline COPD & 15 & $9 / 6$ & $\begin{array}{l}72 \text { (median: } \\
69 \text {, range: } \\
62-89 \text { ) }\end{array}$ & 2 \\
\hline
\end{tabular}


involvement, enabled patients to manage their condition and be alert to changes that would warrant hospital care.

\section{Expert patient and informal carers}

The majority of patients involved in the study lived with a spouse, partner or offspring in their own homes. The patients appeared to be experts in the monitoring and self-management of their condition as a result of living with the illness as a long-term condition over a long period, in case of the COPD group, for many years.

I'm used to it now as you might say after four years of getting it. (A3, COPD)

To cope with the symptoms they experienced, many patients adapted their way of life. As the patients and their informal carers reflected on how their condition had changed their lives, they spoke about the adjustments they had made to make things easier, and further changes they would have to make as their condition deteriorated.

Clearly now I'm getting to the stage where I'm going to be more at home, more disabled in the sense that I can't do so much, I can't walk so far... So clearly life's going to change now, life's going to be very different. Um, so yes you've got to take a day at a time really now and see how it goes. (A9, Lung Cancer)

Most of the patients described how they received a considerable amount of support from their informal carers, particularly their spouse and children, often involving the provision of psychological and practical help. For some, this signalled a significant lifestyle change because of the need to be available for unexpected crises.

I'm very fortunate, I've got a family that look after me... They are good. My daughter-in-law, she's excellent. See comes and stays a couple of nights with me and sleeps here a couple of nights and my son takes me everywhere I want to go. I don't know where I'd be without them actually. I'm going in for this fortnight [respite] to try and give them a break because they don't get no chance to do anything. They can't have a drink on a night in case I'm taken bad and I need the car to be driven anywhere, so he [son] never has a drink on a night. I don't like to be a burden on them like that. Especially when they're doing it out of the goodness of their heart and you don't have to ask them to do it. (C3, COPD)

Members of the family were also generally involved in the decision-making process concerning emergency admission, often calling the ambulance or healthcare professionals.

He got to the top of the stairs, couldn't breathe at all. And I said to him, we're going to have to ring...because you can't go on like this. Anyway, I got him back downstairs and um he wasn't any better and I rang the ambulance. (A10, wife: Lung Cancer)

Some patients had a co-caring relationship with their spouses, with both patients and carers assuming roles according to their needs and abilities. This co-caring relationship was also important in the decisions about hospital admission and hospital stay.

As I say my wife [cries], my wife was...the main problem why I want to get home. I'm worried about her. It's worry about her. (C2, Lung Cancer)

\section{Patient contact with community healthcare professionals}

Exploring the relationship that the patients had with community services provided further insight on the selfmanagement practices they engaged in. For some, community healthcare provision (eg, nurses' home visits) was very important in their management and perceived positively by both patients and their carers.

You do get your visits from the community people to make sure you are ticking over sort of thing. (A2, COPD)

There was a belief, particularly among healthcare professionals, that supporting patients at home with GP and community nurse visits enabled better management of the condition and helped prevent hospital admissions.

He has been managed very well at home over the last 18 months with the help of a very good community matron, so we haven't seen him as much over the last 18 months. (Respiratory CNS, COPD)

While a number of patients felt they had good community healthcare support, which helped them manage their condition, some reported they received little support from healthcare professionals in the community, or were doubtful about the need for this form of support.

[No input from community nurses] at the moment, I mean I can manage as much as I can and my wife helps me, and she does help me a lot. And with her help I can do it then, can't I; I don't think I need a nurse, no. (B8, COPD)

There appeared to be a good deal of uncertainty among a number of patients and their carers concerning who individual community healthcare professionals were and what their role was. This was particularly apparent when patients were trying to distinguish between community matrons, district nurses and specialist palliative care nurses, and their contribution to care. Other participants were unaware of the community support available and its potential usefulness. Consequently, when some participants had been offered such support they either doubted it could help them or felt they did not need it. 
No it's just...well I don't know what rank they are. (A8, Lung Cancer)

Some patients and carers expressed dissatisfaction with their lack of contact with some community health services. The most common problem was about the time they had to wait for GP appointments, followed by the lack of immediate contact with community nurses.

I phoned up once when I was in trouble, but [Community Matron] was on leave and the lady who took the call said I can't get round because I'm finished in ten minutes. (C1, COPD)

This difficulty in accessing support from community services would later reinforce the patients' decisions concerning the need for emergency hospital admission.

In addition, communication between the patients and the community healthcare professionals was variable, and some patients thought it was less effective than it should be. For example, patients did not know the names of professionals responsible for their care, and contact with them was sporadic, which meant some patients were reluctant to contact their designated community healthcare professionals.

The community matrons, like what [name] is, they're supposed to be someone that you can contact at any time. They'll keep you out of hospital...it isn't working for me. (C1, COPD)

Some healthcare professionals were aware of these difficulties, for example:

Now the patient has a community matron, but instead of contacting her when he starts to become ill, he waits for a few days, will become worse and then ring for an ambulance. On this admission the nurse asked patient about his contact with the community matron, he said 'He doesn't like to contact her'. (Respiratory CNS, COPD)

\section{Negotiated decision-making}

The term 'negotiated decision-making' is used here to reflect how the many factors involved in deciding when and who to call for assistance informed the final outcome. Often there was direct negotiation about admission by the patient and carer; on many occasions, this also involved healthcare professionals. Patients and carers drew on past experience of previous admissions, and interpreted advice they had been given by healthcare professionals, or written instructions about what to do in an emergency situation. Patients frequently experienced fluctuations in their symptoms and often faced uncertainty. The following themes were identified as being particularly influential in the decision-making process.

\section{Physical symptoms and anxiety}

As symptoms worsened, with shortness of breath commonly being the most distressing, patients' anxiety also tended to escalate. This was when patients started the process of negotiating the decision to call for help.

Well I hadn't been well for a week and I'd been trying to do it myself, do all the necessary things as I thought. It was with a chest complaint with this COPD, and I gradually got worse. And on the morning in question I got up and I just could not breathe and I couldn't get any breath. I'd got my oxygen on, I'd got all my tablets, I'd got all my inhalers, nothing was helping me. And I basically got scared for the first time. Because I've had this condition now for a few years, but it got really bad and in the end, again for the first time I actually phoned the doctor and said, I needed somebody out. (B11, COPD)

\section{Holding on}

The participants' accounts reveal how they tried to avoid going into hospital for as long as possible, despite their deteriorating clinical situation. Sometimes, this was contrary to the wishes of carers. However, the patients tended to 'hold on' by monitoring their symptoms and using their medication in attempts to alleviate them.

Say on a Saturday I get an exacerbation and it starts to flare up, a chest infection or something like that, then I've got the tablets to start before I can get to see the doctor Monday, so I've got a two day start. So I don't have to wait all over the weekend 'cos I don't like hospitals you see. (C3, COPD)

Some participants reported that if they had sought help from community health services earlier on when their symptoms were deteriorating, things might have been better managed, or they may have avoided the later hospital admission.

Things were getting really bad and I could feel it start to get to me up here [points to chest], and I was getting a little bit annoyed with myself that I didn't, um, do something in fact earlier than last Tuesday. Um, but that's me, that's me, as I say I try and cope and perhaps I try and cope too much. (A8, Lung Cancer)

\section{Past experience}

Decisions about the need for urgent treatment were also taken based on previous experiences. Many of the patients considered what had been effective when they had been faced with deteriorations in their condition in the past and developed a repertoire of potential responses (such as calling their GP or seeking advice from a specialist nurse), who had worked for them at different points. This knowledge also meant they were able to decide when hospital admission was needed.

Once you've got the infection that's it, it's in there and you've got to go to hospital to get this intravenously, it's too strong for the tablets. (A3, COPD) 
Weighing up advice

It was evident that patients and their carers weighed up the advice they were given by healthcare professionals when deciding on the best course of action in an emergency situation. This advice often took the form of discussion of 'hypothetical situations' and possible courses of action that might be required should their condition continue to deteriorate. As noted above, such advice was evaluated in the light of past experience.

I just felt that I wasn't right and what were wrong with me I couldn't put right, I'd got no control over it. So obviously there was something wrong with me internally, I'd got to go to the hospital to get it sorted, which they told me could happen. You know, they told me, if ever you feel ill and your temperature varies ring an ambulance up and get down the A\&E. (B6, Lung Cancer)

In other instances, the advice given was more immediate, often during a current episode, consequently, the patient's decision about whether to follow the advice was made in a much shorter period of time. In some cases, patients thought it best to treat the symptoms at home, and later admission became unavoidable, as there was no improvement in their condition.

He [the patient] said I think we need some help. So I did ring our GP's number and it put me through to like an emergency doctor on call. And there was two came out in the afternoon, wasn't there. And I think they were quite concerned and would have liked him to have gone in then, but [patient's name] is quite stubborn when he wants to be and he said, no I'll be alright, I'll be alright. And they did say to me, if he gets any worse then get an ambulance, which is what we ended up doing, about half past ten at night. (B8 wife, COPD)

\section{Letting go}

While none of the patients wanted to be admitted to hospital, eventually, the need for admission had to be accepted, albeit reluctantly. This was often accompanied by feelings of lack of control and an increased sense of vulnerability. At this point, control was relinquished to ambulance crews and hospital professionals. In their reflections on the admission process the patients were adamant that hospital admission was inevitable because all other options had been exhausted.

I needed to come in, because, although you've got district nurses and that there, they can't do everything. (C7, COPD)

At the point care was handed over to ambulance staff and other healthcare professionals in the emergency unit, the patients recalled an overriding sense of relief.

I was glad to see the hospital. To tell you the truth, I was never so glad to see them [paramedics], they put oxygen on me straight away, give me relief, because I was just choking. (C8, Lung Cancer)
On a number of occasions the ambulance crew discussed options with patients and their carers, such as going to hospital or seeking community care. Both patients and ambulance staff regarded hospital admission as the more efficient method of securing rapid treatment.

They came round [paramedics], checked me over and one of them suggested, he said, well we can either take you in or see your GP. And he said, "personally I would be taken in", you know, his opinion. I mean you go and see your GP they will fix you up next Wednesday can't they, that sort of thing isn't it, usually. So that was virtually it, yes. They did all the checks in the ambulance on the way to the hospital then they took me in there and that was it, you know. (A14, Lung Cancer)

\section{Justified emergency call}

All the patients and carers interviewed considered that admission was justified. Indeed, there was little evidence from the data that patients were using emergency services inappropriately, calling for an ambulance when they could have held on for a GP or community nurse visit, for example.

Sometimes she leaves it, in my opinion, too long before she goes in. But she makes that decision normally but it's never a waste of time, it's always necessary in my opinion. No, we couldn't avoid, we couldn't avoid that, it has to be taken, that's the question you're asking. There was no alternative. (B2 partner, COPD)

This was confirmed by hospital and community healthcare professionals. In fact, for no admission in this group of patients did healthcare professionals believe the admission had not been justified.

It seems that he was quite unwell when he went in. He had a definite infection and that showed up on the chest $\mathrm{x}$-ray, and he was treated quite aggressively on that occasion. So he had nebulised medication for his breathing, he had steroids to take and he also needed intravenous antibiotics. So it would seem that this was a justified admission. (GP, COPD)

\section{DISCUSSION}

The study explored the experiences of patients with lung cancer and COPD, along with that of their carers. The perspectives of healthcare professionals involved in their care were also examined. The findings illustrate the complex interplay of the symptomatic, psychosocial, organisational and temporal factors, which characterise the time leading up to emergency hospital admission. The effects of this combination of factors are evident in the three phases of: self-management of deteriorating symptoms, negotiated decision-making and letting go. The patient and carer are the principal actors in this process, with a variety of healthcare professionals in contributing roles: GPs, community nurses, specialist nurses 
and ambulance crews. The patients' changing clinical condition and psychological state, and their carers' involvement in this process shape the nature of their decision-making.

Most patients, particularly those with COPD, had considerable experience in the self-management of their own illness. This had been developed from dealing with repeated episodes of acute exacerbation. Patients with lung cancer also demonstrated an element of selfmanagement, however, as their illness did not follow the same recurrent pattern of exacerbations and remissions, ${ }^{26}$ their experience and expertise in selfmanagement was more limited.

As the patients' condition deteriorated, they entered the phase of negotiated decision-making where hospital admission was being considered, while continuing to selfmanage their symptoms. The patient often continued to 'hold on' trying to avoid admission, while often seeking advice about how to manage their illness. As their condition deteriorated the anxiety levels of the patients and carers increased. Patients and carers also drew on past experience of similar episodes, including recalling advice that had been given to them previously by health professionals.

The third phase, letting go, occurred once the patient had made the decision, often reluctantly, to accept hospital admission. Patients often attempted to retain a level of independence in the management of their condition. However, as symptoms deteriorated and anxiety increased, patients reached a threshold and relinquished their care to health professionals. At this point, they experienced relief that ambulance assistance and hospital care was available to them.

Purdy and Griffin ${ }^{4}$ observed that healthcare professionals' decisions to admit patients to hospital were complex and usually made taking account of the patient's current state of health, concerns, expectations, existing comorbidities and available social support. Our study suggests that the patients' decision-making process is equally complex. Without exploring these issues from both the patient's and healthcare professional's perspectives, it is difficult to have a clear understanding of how emergency admissions occur. Thus, taking a qualitative approach in this study enabled us to gain some valuable insights on this important area.

As current efforts to reduce emergency admissions are based on the belief that many are 'inappropriate', ${ }^{13}$ our findings challenge this assumption as no healthcare professional thought this to be the case with these admissions. It may be that admissions with advanced disease are less avoidable than is sometimes assumed. This is supported by a recent survey conducted in two large hospitals, which concluded that the admission of only $6.7 \%$ of patients with palliative care needs could have been avoided. ${ }^{16}$ This suggests an important need-to realign our understanding of inappropriate admission, and for policy-makers to recognise that reducing admissions to improve efficiency may not be appropriate.
The self-management undertaken by the patients with COPD interviewed for this study is recognised as important for enabling patients to remain at home, and increases their sense of control over their illness. ${ }^{27}$ Interventions to enable self-management can be effective in reducing hospital admissions ${ }^{14}$ however, patients also need assistance from skilled healthcare professionals at this time.

Patients with advanced disease frequently receive care from community nurses. ${ }^{28}{ }^{29}$ In this study, some patients had visits from community nurses before admission, and for patients with lung cancer, the nurse was sometimes involved in the admission decision. Although 'community case management' coordinated by community matrons ${ }^{30}$ and other outreach interventions designed to reduce COPD admissions have been introduced, ${ }^{31}$ evidence of their effectiveness in reducing admissions is lacking. ${ }^{32}$ Community COPD outreach services were available to patients in the study areas, although few of the participants received them. As we only explored the experiences of patients who had been admitted as emergencies we cannot comment whether or not these local services were effective for others.

A number of our patients had access to specialist palliative care services in the community. While specialist palliative care can be effective in improving patients' symptoms and quality of life, ${ }^{33} 34$ a recent meta-analysis reported minimal impact of community specialist palliative care nursing services among the better methodological studies. ${ }^{35}$ A Canadian study suggests that a physician-led community specialist palliative care service can be effective in reducing hospital use at the end of life. ${ }^{36}$ All the areas covered in this study had such a service although none of the participants reported that they had received services directly from such specialists. Whether those who were in use of such services were not admitted in the locality of this study is unknown. This suggests that further research is needed into specialist community services, their impact on patients' quality of care, and on reduction in hospital usage. ${ }^{37}$

Coordination and integration of care led by GP and primary care teams in the community is important in ensuring patients with advanced illness receive the care they need. ${ }^{38}$ While GP involvement in care was evident and appreciated by a number of our participants, others revealed that they did not see their GP very often, and for some the oncology clinic had taken on the role of principal medical carer.

\section{Limitations}

The study has some limitations. We were unable to interview some of the patients identified because they were too unwell to be recruited. However, patients, particularly in the lung cancer group had a median survival of $<3$ months suggesting we were still able to observe the experience of patients near the end of life. Patients with COPD had longer survival (only 2 of the 15 died in this time), consistent with COPD trajectories being more 
protracted. ${ }^{23}$ Interviews were shorter than what we hoped, and we were unable to discuss the experience of some patients in depth because they were easily fatigued. Also, it was not always possible to recruit healthcare professionals who had been directly involved in the patients' care at the time of admission, so the insights we gained were limited.

\section{CONCLUSIONS}

The process by which patients with advanced lung cancer and COPD are admitted to the hospital as an emergency is complex with interaction between symptom, psychosocial, temporal and organisational factors. Our understanding of this complex process may enable healthcare providers to intervene to prevent some emergency hospital admissions. However, in this patient population with advanced disease, there is likely to be the need for emergency admission to treat severe acute symptoms.

\section{Author affiliations}

${ }^{1}$ Warwick Manufacturing Group (WMG), University of Warwick, Coventry, UK ${ }^{2}$ Division of Health Sciences, Warwick Medical School, University of Warwick, Coventry, UK

${ }^{3}$ School of Nursing, Institute of Clinical Sciences, University of Birmingham, Birmingham, UK

${ }^{4}$ Division of Health Sciences, Royal College of Nursing Research Institute, Warwick Medical School, University of Warwick, Coventry, UK.

Acknowledgements The authors would like to thank the patients with cancer and chronic obstructive pulmonary disease, their families and the healthcare professionals who gave their time generously and shared their experiences and insights. They would also like to acknowledge the contribution of Fran Badger to the primary data collection and analysis. Finally, the authors would like to thank Roberta Lovick for her valuable advisory input throughout the study as expert service user.

Contributors EK was involved in project management, study design, collecting data, analysis of data and drafting of the manuscript. DM was involved in study conception and design, data analysis, and co-drafting the manuscript. CB was involved in study design, collecting data, analysis of the data, and edited the manuscript for important content. SS was involved in study conception, led on the patient and public involvement activity and edited the manuscript for important content. AH was involved in analysis of data and editing the manuscript for important content. FG was involved in study conception and design, and edited the manuscript for important content.

Funding This work was supported by a grant from Macmillan Cancer Support. Also, the research team acknowledges the support of the National Institute for Health Research, through the National Cancer Research Network.

Competing interests None declared.

Ethics approval Ethical approval was granted by the NHS regional ethics committee (Ref 11/H1202/1).

Provenance and peer review Not commissioned; externally peer reviewed.

Data sharing statement No additional data are available.

Open Access This is an Open Access article distributed in accordance with the Creative Commons Attribution Non Commercial (CC BY-NC 4.0) license, which permits others to distribute, remix, adapt, build upon this work noncommercially, and license their derivative works on different terms, provided the original work is properly cited and the use is non-commercial. See: http:// creativecommons.org/licenses/by-nc/4.0/

\section{REFERENCES}

1. Jones R. Bed occupancy: the impact on hospital planning. $\mathrm{Br} \mathrm{J}$ Healthc Manag 2011;17:307-13.

2. Blunt I, Bardsley M, Dixon J. Trends in emergency admissions in England 2004-2009: is greater efficiency breeding inefficiency. The Nuffield Trust, 2010.

3. Department of Health. Emergency admissions to hospital: managing the demand. National Audit Office. HC 739. London: The Stationery Office, 2013.

4. Purdy S, Griffin T. Reducing hospital admissions. Guidance should be evidence based and take a holistic view of patient care. BMJ 2008;336:4-5

5. HES. HESOnline: headline figures, 2010-11. London: NHS Information Centre, 2011.

6. Calderón-Larrañaga A, Carney L, Soljak M, et al. Association of population and primary healthcare factors with hospital admission rates for chronic obstructive pulmonary disease in England: national cross-sectional study. Thorax 2011;66:191-6.

7. Buckingham R, Lowe D, Pursey N, et al. Report of the national chronic obstructive pulmonary disease audit 2008. Clinical audit of COPD exacerbations admitted to acute NHS units across the UK. Royal College of Physicians, 2008.

8. Yates M, Barrett A. Oncological emergency admissions to the Norfolk and Norwich University hospital: an audit of current arrangements and patient satisfaction. Clin Oncol (R Coll Radiol) 2009;21:226-33.

9. Royal College of Physicians and Royal College of Radiologists. Cancer patients in crisis: responding to urgent needs. Report of a working party. London: RCP, 2012.

10. Schofield I, Knussen C, Tolson D. A mixed method study to compare use and experience of hospital care and a nurse-led acute respiratory assessment service offering home care to people with an acute exacerbation of Chronic Obstructive Pulmonary Disease. Int $J$ Nurs Stud 2006;43:465-76.

11. O'Cathain A, Knowles E, Maheswaran R, et al. A system-wide approach to explaining variation in potentially avoidable emergency admissions: national ecological study. BMJ Qual Saf 2014;23: 47-55.

12. Gillam S. Rising hospital admissions. BMJ 2010;340:c636.

13. Roland M, Abel G. Reducing emergency admissions: are we on the right track? BMJ 2012;345:e6017.

14. Purdy S. Avoiding hospital admissions: what does the research evidence say. King's Fund, 2010.

15. Royal College of Nursing. Moving care to the community: an international perspective. RCN Policy and International Department Policy briefing 12/13. 2014

16. Gott M, Gardiner C, Ingleton C, et al. What is the extent of potentially avoidable admissions amongst hospital inpatients with palliative care needs? BMC Palliat Care 2013;12:9.

17. Munday D. Exploring complexity in community palliative care: a practitioner based approach to research and development $[\mathrm{PhD}$ thesis]. University of Warwick, 2007.

18. Staniszewska S, Churchill N. Patients' experiences in the UK: future strategic directions. Patient Exp J 2014;1:140-3.

19. Staniszewska S, Boardman F, Gunn L, et al. The Warwick Patient Experiences Framework: patient-based evidence in clinical guidelines. Int J Qual Health Care 2014;26:151-7.

20. Flanagan JC. The critical incident technique. Psychol Bull 1954;51:327-58.

21. Miles M, Huberman A. Qualitative data analysis. 2nd ed. London: Sage, 1994:172-238.

22. Braun V, Clarke V. Successful qualitative research: a practical guide for beginners. London: Sage, 2013.

23. Ragin C. Turning the tables: How case-oriented research challenges variable- oriented research. Comp Soc Res 1997:16:27-42.

24. King N. Using templates in the thematic analysis of texts. In: Cassell $\mathrm{C}$, Symon G, eds. Essential guide to qualitative methods in organizational research. London: Sage, 2004: 256-70.

25. Gerrish K, Lacey A, eds. The research process in nursing. 5th edn Oxford: Blackwell Publishing, 2006.

26. Murray SA, Kendall M, Boyd K, et al. Illness trajectories and palliative care. BMJ 2005;330:1007-11.

27. Corben S, Rosen R. Self-Management for long-term conditions: patients' perspectives on the way ahead. London: The King's Fund, 2005.

28. King N, Melvin J, Ashby J, et al. Community palliative care: role perception. Br J Community Nurs 2010;15:91-8.

29. Walshe C, Luker KA. District nurses' role in palliative care provision: a realist review. Int J Nurs Stud 2010;47:1167-83. 
30. Wilson T, Buck D, Ham C. Rising to the challenge: will the NHS support people with long term conditions? BMJ 2005;330:657-61.

31. Williams V, Smith $A$, Chapman L, et al. Community matrons-an exploratory study of patients' views and experiences. J Adv Nurs 2011;67:86-93.

32. Wong CX, Carson KV, Smith BJ. Home care by outreach nursing for chronic obstructive pulmonary disease. Cochrane Database Syst Rev 2012;4:CD000994.

33. Higginson IJ, Evans CJ. What is the evidence that palliative care teams improve outcomes for cancer patients and their families? Cancer J 2010;16:423-35.

34. Bakitas M, Lyons KD, Hegel MT, et al. Effects of a palliative care intervention on clinical outcomes in patients with advanced cancer: the project ENABLE II randomized controlled trial. JAMA 2009;302:741-9.
35. Luckett T, Davidson PM, Lam L, et al. Do Community specialist palliative care services that provide home nursing increase rates of home death for people with life-limiting illnesses? A systematic review and meta-analysis of comparative studies. J Pain Symptom Manag 2013;45:279-97.

36. Seow H, Brazil K, Sussman J, et al. Impact of community based, specialist palliative care teams on hospitalisations and emergency department visits late in life and hospital deaths: a pooled analysis. BMJ 2014;348:g3496.

37. Murtagh F. Can palliative care teams relieve some of the pressure on acute services? BMJ 2014;348:g3693.

38. Mason B, Epiphaniou E, Nanton V, et al. Coordination of care for individuals with advanced progressive conditions: a multi-site ethnographic and serial interview study. Br J Gen Pract 2013;63: e580-e8. 